\title{
Diálogo sobre a relação de ensino-aprendizagem na disciplina de Física com estudantes de nível médio
}

\author{
Dialogue on the teaching-learning relationship in the discipline of Physics with high school
}

students

Diálogo sobre la relación enseñanza-aprendizaje en la disciplina de la Física con estudiantes de secundaria

Recebido: 14/10/2021 | Revisado: 23/10/2021 | Aceito: 28/10/2021 | Publicado: 30/10/2021

Bruno Aguiar Sfredo
ORCID: https://orcid.org/0000-0002-2928-9640
Instituto Federal de Educação, Ciência e Tecnologia de Mato Grosso, Brasil
E-mail: brunosfredo.pessoal@gmail.com
Jéssica de Oliveira Andrade Borges
ORCID: https://orcid.org/0000-0001-6719-0898
E-mail: jessicaandrade776@gmail.com
Ana Claudia Tasinaffo Alves
Instituto Federal de Educação, Ciência e Tecnologia de Mato Grosso, Brasil
ORCID: https://orcid.org/0000-0003-0670-1978
Instituto Federal de Educação, Ciência e Tecnologia de Mato Grosso, Brasil
E-mail: ana.alves@ifmt.edu.br

\section{Resumo}

Culturalmente criou-se uma visão na qual a Física é uma disciplina considerada complexa tanto no Ensino Médio como também no Ensino Superior. Diante disso, o presente estudo objetivou avaliar a percepção dos estudantes sobre a relação ensino-aprendizagem na disciplina de Física e identificar os problemas citados por eles que dificultam de alguma forma esta relação. A pesquisa é do tipo mista, e os dados foram obtidos por meio de um questionário contendo 6 questões objetivas e discursivas, que foi aplicado de forma pessoal e individual para estudantes do Ensino Médio matriculados nas 3 principais escolas públicas do município de Confresa-MT, o questionário foi aplicado a 263 estudantes entre os meses de abril a outubro de 2019. Pela análise dos dados, foi possível verificar que $58,17 \%$ dos estudantes avaliam o processo de ensino-aprendizagem como ótimo ou bom e parte dos estudantes relacionaram a qualidade do processo com a forma como o professor ministra as aulas, consideraram ainda que para ter sucesso neste processo é necessário que todo o meio esteja em harmonia, dentre os principais problemas citados estão: dificuldade do professor em explanar os conteúdos, distrações, falta de interesse e mau comportamento da sala em geral. Como pontos para melhorar a qualidade do processo citaram: mudar o método de explanação dos conteúdos, aulas mais dinâmicas, e mais interação entre docente e estudante.

Palavras-chave: Dificuldade de aprendizagem; Ensino-aprendizagem; Ensino de Física.

\begin{abstract}
Culturally, a view was created in which Physics is a discipline considered complex both in High School and in Higher Education. Therefore, this study aimed to assess the perception of students about the teaching-learning relationship in the discipline of Physics and identify the problems mentioned by them that somehow hinder this relationship. The research is of a mixed type, and data were obtained through a questionnaire containing 6 objective and discursive questions, which was applied personally and individually to high school students enrolled in the 3 main public schools in the city of Confresa-MT, the questionnaire was applied to 263 students between the months of April and October 2019. Through data analysis, it was possible to verify that $58.17 \%$ of the students rate the teaching-learning process as great or good and some students related the quality of the process with the way the teacher teaches classes, even considering that to have Success in this process requires that the whole environment is in harmony, among the main problems mentioned are: teacher's difficulty in explaining the contents, distractions, lack of interest and bad behavior in the classroom in general. As points to improve the quality of the process, they mentioned: changing the content explanation method, more dynamic classes, and more interaction between teacher and student.
\end{abstract}

Keywords: Learning difficulty; Teaching-learning; Teaching Physics.

\section{Resumen}

Culturalmente, se creó una visión en la que la Física es una disciplina considerada compleja tanto en el Bachillerato como en la Educación Superior. Por tanto, este estudio tuvo como objetivo evaluar la percepción de los estudiantes 
sobre la relación enseñanza-aprendizaje en la disciplina de la Física e identificar los problemas mencionados por ellos que de alguna manera dificultan esta relación. La investigación es de tipo mixto, y los datos se obtuvieron a través de un cuestionario que contiene 6 preguntas objetivas y discursivas, el cual se aplicó personal e individualmente a estudiantes de secundaria matriculados en las 3 principales escuelas públicas de la ciudad de Confresa-MT, se aplicó el cuestionario a 263 estudiantes entre los meses de abril y octubre de 2019. A través del análisis de datos, se pudo constatar que el 58,17\% de los estudiantes califica el proceso de enseñanza-aprendizaje como bueno o bueno y algunos estudiantes relacionaron la calidad del proceso con la forma en que el docente imparte las clases, aun considerando que para tener Éxito en este El proceso requiere que todo el entorno esté en armonía, entre los principales problemas mencionados se encuentran: dificultad del docente para explicar los contenidos, distracciones, desinterés y mal comportamiento en el aula en general. Como puntos para mejorar la calidad del proceso, mencionaron: cambio de método de explicación de contenido, clases más dinámicas y más interacción entre profesor y estudiante.

Palabras clave: Dificultad de aprendizaje; Enseñanza-aprendizaje; Enseñanza de la Física.

\section{Introdução}

A educação contemporânea tem como um de seus principais pilares o constante debate dentro da comunidade escolar, este debate é abrangente e busca abordar os mais variados temas que de alguma forma possam influenciar o processo de ensino-aprendizagem. Dentre estes temas, um que nos chama atenção é o ensino da disciplina de Física.

No Brasil, a disciplina de Física até o final do século XIX era considerada uma disciplina secundária, pois, os modelos de ensino da época tinham como foco as ciências humanas. Apenas no início do século XX a Física atinge um status de relevância dentro do sistema de ensino. Entretanto este fato não acontece por acaso, ele está diretamente relacionado a inúmeros acontecimentos históricos, que somados foram de extrema importância para o desenvolvimento das ciências exatas. Dentre eles destacam-se, a abolição da escravatura, a chegada de grande contingente de imigrantes e a experiência de um novo regime político (República), que aconteceram exatamente na época do primeiro surto industrial (Haidar, 1972)

Um importante ponto a ser citado, é que desde a sua introdução como disciplina padrão no sistema de ensino brasileiro, a Física não foi uma disciplina preferida entre os estudantes, este fato é constatado a partir da literatura da época, que retrata pouca frequência nas turmas. Essa problemática atingiu tanto o Ensino Básico como o Ensino Superior. Este fator, com o passar do tempo, acabou gerando como consequência um dos principais problemas na área, a falta de professores formados em Física aptos para ministrar a disciplina nas escolas (Sampaio, 2004).

Estes fatores estenderam-se até os dias atuais, acarretando debates frequentes, quase sempre motivados pelo baixo rendimento dos estudantes na disciplina, em que na maioria das vezes atribui-se majoritariamente este baixo rendimento a fatores específicos relacionados aos estudantes como, dificuldade de concentração, falta de interesse e dificuldades de aprendizagem.

Em um estudo exploratório com o mesmo eixo temático que esse presente texto, realizado com 350 estudantes, identificou que 45,5\% dos pesquisados gostam da disciplina de Física. Os principais motivos por eles elencados é o gosto por cálculos, mas muitos não conseguiram explicar o porquê gostava da disciplina. Foi possível identificar um distanciamento dos estudantes com a disciplina de Física. Não conseguiam, por exemplo, explicar a importância da disciplina. Ficou evidente ainda que existe um bloqueio com relação à aprendizagem dos estudantes. Além disso, os autores identificaram que a falta de metodologias dinâmicas e atrativas usadas em aulas era um dos principais agravantes da falta de gosto pela disciplina (Ricardo \& Freire, 2007).

Se pegarmos estes fatores e estabelecermos parâmetros históricos podemos afirmar que em sua maioria estão diretamente ligados a uma visão cultural enraizada nas escolas brasileiras, e entendem que Física é uma disciplina extremamente complicada, com conceitos de difícil compreensão. Essa visão gera bloqueios até hoje na aprendizagem dos estudantes. Estes fatores associados entre si instigaram-me a questionar, qual a percepção que os estudantes de Ensino Médio da cidade de Confresa-MT possuem sobre a relação ensino-aprendizagem na disciplina de Física? 
Embasado por esta problemática, o presente texto é resultado de um estudo que objetivou avaliar a percepção dos estudantes sobre a relação ensino-aprendizagem na disciplina de Física e identificar os problemas citados por eles que dificultam de alguma forma esta relação. Assim surgiram questões que nortearam esse estudo, como: quais os principais problemas encontrados durante as aulas de Física? Como eles qualificam a relação estudante-professor dentro da sala de aula? E quais os pontos em que eles sugerem mudanças efetivas para a evolução do processo educativo?

\section{Contexto do Ensino de Física no Brasil}

O ensino de Física chegou ao Brasil junto com o imperialismo, uma das primeiras modificações realizadas por Dom Pedro II na educação após expulsar os jesuítas, foi incluir as chamadas ciências fundamentais (Matemática, Astronomia, Física, Química, Biologia e Sociologia). O ensino dessas ciências era superficial, suficiente apenas para que o estudante não fosse um completo analfabeto nestas áreas. As mudanças implantadas no período imperial não foram muito substanciais, e a educação neste período passou por tempos turbulentos em função de uma série de problemas gerados com a saída dos jesuítas da educação do país (Almeida Junior, 1980).

O sistema educacional brasileiro efetivou-se a partir do início da primeira república, e foi a partir desta efetivação que o sistema passou a evoluir de forma significativa, embora estivesse sob entraves políticos constantes. Apesar de todas as reformas no sistema educacional, o Ensino de Ciências, em especial o Ensino de Física, sempre estiveram historicamente posicionados em segundo plano dentro dos debates da educação (Almeida Junior, 1980). “As reformas educacionais do primeiro período republicano mostraram uma educação ilusoriamente científica de aspiração contemporânea, ficando longe de realizar uma legítima formação de cientistas por meio de profundos estudos das ciências exatas, sem detrimento da parte experimental (Almeida Junior, 1980, p. 59).

Dentre as principais mudanças relacionadas ao ensino de Física efetivadas no primeiro período da república, é possível citar a obrigatoriedade de cursar as disciplinas científicas. Outra mudança a ser destacada, e talvez a mais significativa que foi proposta, é a determinação pela aplicação dos métodos experimentais a fim de instigar os estudantes a terem gosto pelas ciências, entretanto não foi completamente implantada (Almeida Junior, 1980).

Os principais motivos que impediram o avanço da metodologia científica pelas escolas brasileiras era:

[...] carência de recursos nas escolas, pelo baixo nível do professorado, pela inexistência de faculdades de licenciaturas, pela fiscalização deficiente que, quando não era omissa fazia-se cúmplice e, sobretudo, pela mentalidade vigente de intelectuais orientadores de ensino que, formados na tradição escolástica, acadêmica e sem vida, se oponha a quaisquer transformações mais profundas no sistema de ensino, por tudo isso, as propostas de lei não se concretizavam totalmente e não se constituíram num crescente espírito científico que moldasse as novas gerações de professores (Almeida Junior, 1980, p. 61).

Apesar destes motivos citados, a pesquisa no Ensino de Física passou por um período estável, e era possível dizer que o país tinha uma condição razoável ao menos nos principais centros. A tradição nessa área é reconhecida internacionalmente, possui encontros nacionais e pós-graduação desde a década de 1980. Conta ainda com revistas especializadas, simpósios, oficinas, projetos, livros e diversos outros materiais que foram desenvolvidos após a consolidação do Ensino de Física no país. É possível observar a marca deixada nos recursos produzidos por grandes pesquisadores e professores ao longo dos anos (Moreira, 2018).

Entre os fatores que faz com que o Ensino de Física seja considerado ruim, está a desvalorização do professor da Educação Básica, muitas vezes as condições de trabalho não favoráveis, elevado quantitativo de estudante em sala, carga horária exaustiva, baixo salário, falta de formação continuada e currículo fechado (Moreira, 2018). 
A evasão dos cursos de Física é outro fator agravante e tem contribuído para a falta de profissionais qualificados para atuarem na educação. Um dos motivos elencados para a evasão é a reprovação em disciplinas, conflitos entre os professores e estudantes gerados pela falta de diálogo e a falta de empatia e por uma hierarquia estabelecida, que muitas vezes domina os estudantes e não encontram espaços para discussões (Fernandes et. al., 2020).

É importante considerarmos que há condições e situações distintas no Ensino de Física no Brasil. O Ensino Superior apesar de ser baseado em sua maior parte no modelo tradicional de ensino, centrado na figura do professor, oferece aos acadêmicos, boas condições de materiais, tanto teóricos, quanto físicos, para auxílio da aprendizagem, além de laboratórios que em boa parte oferecem condições mínimas para realizar as atividades curriculares exigidas (Moreira, 2018).

Entretanto, quando partimos para uma análise do Ensino Básico, nos deparamos com uma situação completamente diferente, o grau de defasagem em muitas escolas chega a ser assustador. O Estado não fornece suporte para que haja um ensino de qualidade, faltam laboratórios, materiais didáticos, as salas de aulas muitas vezes estão em péssimas condições, além de um modelo de ensino que não facilita o processo educativo e o progresso do Ensino de Física (Moreira, 2018).

Outros fatores elencados como obstáculos no Ensino de Física, especialmente no Ensino Básico e em escolas públicas, é a ausência de práticas experimentais, profissionalização insuficiente dos professores, número reduzido de aulas, e a dependência excessiva do livro didático (Costa \& Barros, 2015). Há de se considerar ainda, que existe uma lacuna entre os conteúdos que são ministrados e a vivências dos estudantes, e muitas vezes é verificado uma aversão deles frente aos conteúdos da disciplina de física (Silva; Toledo \& Carbo, 2020).

Essa não é uma realidade agradável, portanto, não muito distante da realidade atual do Ensino de Física. Além das problemáticas mencionadas acima, muitas vezes as aulas não atendem a realidade dos estudantes. Para tentar amenizar essa problemática é necessário promover momentos de debates e interação entre os estudantes, para que estes possam expor seus anseios, queixas e dificuldades enfrentadas e dessa forma, aumentar o interesse e a participação dos estudantes na disciplina (Morais, 2009).

\section{Fatores que contribuem para o Ensino de Física}

Sabe-se que a experimentação no Ensino de Física pode atuar como facilitador do processo de ensino, pois visa motivar e estimular os estudantes. Contudo, ao planejar uma atividade experimental o professor precisa promover a participação dos estudantes, e não apenas os transformar em meros espectadores (Reis \& Macêdo, 2015). As aulas práticas em si não desenvolvem nos estudantes o pensamento crítico, para isso, é necessário problematizar e mostrar os caminhos para se chegar aos resultados (Cardoso, 2020).

Nas escolas com laboratório escolar, muitas vezes são usados por professores de forma equivocada. Existe um foco na exclusiva preparação de montagens e realização de medidas pelos estudantes, quase sempre, se distancia do fazer ciência. As aulas práticas não podem envolver apenas manipulação de objetos e equipamentos com o propósito de constatar fatos, mas, sobretudo, deve ocorrer a interpretações de ideias sobre observações e fenômenos, com o propósito de produzir conhecimentos aplicáveis na vida dos estudantes (Borges 2002).

Cabe destacar que o Ensino de Física não deve se restringir apenas a sala de aula e a laboratórios. Existe atualmente muita discussão sobre o uso de espaços considerados não formais, espaços esses que podem ser os mais variados possíveis. Para a escolha do espaço de ensino, deve ser analisado o contexto na qual o estudante está inserido e observar as potencialidades para se trabalhar conceitos Físicos. Sabe-se, portanto, que esses espaços podem despertar a curiosidade e o desenvolvimento de habilidades dos estudantes (Barros \& Martins, 2020).

Existe um grande quantitativo de materiais para aulas práticas disponíveis atualmente, mas nem todos favorecem o ensino-aprendizagem e a criticidade dos estudantes. Um estudo analisou um material paradidático, disponível na revista 
Ciência Hoje das Crianças (CHC) e distribuído pelo Programa Nacional do Livro e do Material Didático (PNLD) e constatou que a CHC não segue as recomendações para o ensino de ciências, pois apresentam atividades experimentais com “características empírico-indutivistas marcadas por uma visão rígida da Ciência. Permitem pouca ou nenhuma liberdade para atuação criativa e reflexiva dos estudantes, sem espaço para erro ou discussão dos resultados" e ainda não fica explícito a alfabetização científica (Martins \& Oliveira, 2020, p. 455).

Não é possível conceber a experimentação no Ensino de Física dissociado da teoria, visto que, essa relação permite professores e estudantes atribuírem significados a temas estudados, entenderem o papel da Física para a construção humana, reconhecerem a importância de conceitos físicos para a compreensão de fenômenos da natureza e se atentarem para as contribuições do Ensino de Física para a formação cidadã (Pereira, 2020, p.4).

Além da experimentação no Ensino de Física é imprescindível superar o "ensino fragmentado, linear e descontextualizado" (Sestari et. al., 2021, p. 904). Visto que, essa segmentação pode levar a uma série de equívocos tanto para os professores como para os estudantes (Coelho, 2021). Na prática, faz-se necessário romper os limites da disciplina em foco, priorizar e favorecer a constante busca pelo conhecimento e se utilizar da realidade do estudante para promover uma aprendizagem mais significativa (Sestari et. al., 2021).

Uma das dificuldades em se trabalhar com a interdisciplinaridade no Ensino de Física pode estar relacionado com a formação inicial dos professores. Um estudo realizado por Ferreira \& Custódio (2021) analisou as ementas dos cursos de Licenciatura em Física, e relatam que as temáticas que envolvem a natureza da ciência e saberes pedagógicos possuem um percentual muito baixo em relação a carga horária do curso, menos de $5 \%$. A maioria das disciplinas priorizam os conhecimentos e métodos da ciência e se afasta da didática e dos métodos para ensinar Física.

As tecnologias também podem auxiliar o processo de ensino-aprendizagem dos estudantes, uma vez que tenham os recursos necessários, "formação do professor e uma metodologia de ensino adequada". O uso das tecnologias pode criar um ambiente de imersão do estudante, com aulas interativas, dinâmicas e ativas. É esse dinamismo e interação que agrega ao ensino, pois as tecnologias dissociadas de planejamento e objetivos definidos não favorecem o processo de ensino (Pszybylski et. al., 2020, p. 423).

\section{Metodologia}

O presente estudo foi embasado por uma pesquisa mista que "é uma abordagem de investigação que combina ou associa as formas qualitativa e quantitativa" (Creswell, 2007, p. 27). Esta pesquisa buscou combinar os dois métodos, com o intuito de organizar os dados de características qualitativas em um modo quantitativo para que facilitasse a apresentação e compreensão dos resultados obtidos. Para a realização deste estudo foi utilizado como instrumento de coleta de dados um questionário, contendo seis questões, sendo, duas de respostas fechadas e quatro abertas.

O questionário foi constituído pelas seguintes questões: 1- Como você qualificaria seu rendimento em relação a sua aprendizagem na disciplina de Física? 2- Como você qualificaria as aulas ministradas pelo seu professor de Física? (Para estas duas questões foi oferecido as seguintes opções para os estudantes ( ) Ótimo, ( ) Bom, ( ) Ruim, ( ) Péssimo. 3 - Cite três motivos que você acredita que atrapalham seu rendimento nas aulas de Física. 4- De uma forma geral, você considera as aulas satisfatórias para a completa aprendizagem do conteúdo? Justifique. 5- De acordo com sua visão, indique os principais pontos cuja melhora contribuiria para a evolução do processo de ensino-aprendizagem dos conteúdos de Física. 6- Quantas aulas por semana você tem da disciplina de Física? Você considera a quantidade de aulas semanais suficientes para sua aprendizagem dos conteúdos? Explique.

O questionário foi aplicado presencialmente a 263 estudantes matriculados no Ensino Médio das três principais instituições de Ensino Básico do município de Confresa-MT, são elas, Escola Estadual 29 de Julho (107), Escola Estadual da 
Polícia Militar Tiradentes cabo Moura (86) e Instituto Federal do Mato Grosso - Campus Confresa (70). Todas as instituições assinaram termo de consentimento. Os dados foram coletados entre os meses de abril a outubro de 2019.

Importante destacar que se optou pelo questionário composto por questões abertas e fechadas, de modo que o estudante tivesse liberdade para responder rigorosamente conforme suas perspectivas, para tanto, os questionários não exigiram identificação, e o tempo para responder ao questionário também foi aberto, fornecendo aos estudantes liberdade para que refletissem sobre o tema antes de responder.

É importante destacar que em todas as turmas que foi aplicado o questionário, foi realizado um diálogo antes da aplicação, que tinha como objetivo explicar o foco do estudo, foi explicado a eles a importância da perspectiva deles para o progresso do ensino de modo geral e em especial do Ensino de Física e foi esclarecido também as dúvidas sobre o questionário.

Adiante, na discussão dos resultados obtidos os estudantes receberão numeração de acordo com a escola a qual ele participava, essas numerações seguirão o seguinte padrão, I1, I2, I3... para os estudantes do IFMT; J1, J2, J3... para os estudantes da Escola 29 de Julho e T1, T2, T3... para os estudantes da escola Tiradentes.

\section{Resultados e Discussão}

A discussão dos resultados obtidos terá um tratamento com enfoque qualitativo, entretanto aspectos estatísticos serão de suma importância ao decorrer da análise dos dados, para que se tenha noção da abrangência de determinados resultados obtidos.

Para a pergunta 1 "Como você qualificaria seu rendimento em relação a sua aprendizagem na disciplina de Física?" Foi apresentado aos estudantes 4 alternativas para que eles escolhessem em qual o seu rendimento se encaixava, são elas: Ótimo, Bom, Ruim e Péssimo. Em todas as escolas a maior porcentagem dos estudantes classificaram o rendimento pessoal na disciplina como Bom, como disposto no Quadro 1.

Quadro 1 - Rendimento dos estudantes de acordo com suas percepções.

\begin{tabular}{|c|c|c|c|}
\hline Escola & Ótimo & Bom & Ruim/Péssimo \\
\hline 29 de julho & $10(3,8 \%)$ & $54(50,46 \%)$ & $38(14,45 \%)$ \\
\hline Tiradentes & $3(1,1 \%)$ & $44(51,16 \%)$ & $(39) 14,82 \%$ \\
\hline IFMT Campus Confresa & $6(2,3 \%)$ & $536(1,42 \%)$ & $26(9,88 \%)$ \\
\hline
\end{tabular}

Fonte: Dados da pesquisa (2020).

Um percentual muito próximo, foi obtido por Ricardo e Freire (2007) em um estudo semelhante e de certa forma surpreendeu devido a grande diferença nas metodologias de ensino das escolas retratadas e na estrutura escolar. Entretanto ficou evidente que os estudantes possuem uma visão positiva do seu aprendizado pessoal na disciplina.

Pode-se ainda somar a esta porcentagem de rendimento Bom aos resultados da classificação Ótimo, e a partir desta soma termos uma visão ampla por meio do percentual de estudantes que consideram seu rendimento satisfatório. A opção Ótimo teve os seguintes resultados:

Os estudantes que consideram seu rendimento como Ótimo e Bom somam 58,17\%. Este resultado contraria o senso comum, e se ao comparar os resultados obtidos por Morais (2009) praticamente não há variação nas respostas dos estudantes.

Já se tratando dos resultados negativos a porcentagem de estudantes que consideraram seus rendimentos como Ruim ou Péssimos, seguem descritos no Quadro 3: 
Soma-se $39,15 \%$ os estudantes que consideram seu desempenho insatisfatório. Estas altas taxas de avaliações negativas quanto ao próprio rendimento, nos indicam que os estudantes fazem uma autoavaliação e uma cobrança com relação ao próprio aprendizado, isto deve ser visto de maneira positiva, pois é na autoavaliação, que o estudante irá refletir sobre si mesmo e a construção do conhecimento realizado.

A outra linha de raciocínio segue em direção oposta, e questiona se estes estudantes são realmente capazes de responder se recebem um ensino de qualidade, e este raciocínio embasa-se no fato de que: “o indivíduo é moldado pelo meio em que convive" (Durkheim, 1922), assim, se o indivíduo foi moldado desde a infância por um ensino de má qualidade logo ele irá considerar este ensino bom, não pelo ensino de fato ser bom, mas por ele não conhecer um ensino de qualidade e não ter parâmetros para comparação.

Para a Questão 2, "Como você qualificaria as aulas ministradas pelo seu professor de Física?” Os resultados estão organizados no Quadro 2, os estudantes tinham como alternativas de respostas a opção ótimas ou boas e ruins ou péssimas.

Quadro 2 - Avaliação das aulas do professor na percepção dos estudantes.

\begin{tabular}{|c|c|c|}
\hline Escola & ótimas/boas & ruins/péssimas \\
\hline 29 de julho & $68(25,85 \%)$ & $36(13,69 \%)$ \\
\hline Tiradentes & $65(24,71 \%)$ & $21(7,98 \%)$ \\
\hline IFMT Campus Confresa & $43(16,34 \%)$ & $27(10,27 \%)$ \\
\hline
\end{tabular}

Fonte: Dados da pesquisa (2020).

A partir dos resultados da segunda questão, observou-se um alinhamento com os resultados da primeira questão. Observa-se que 66,9\% dos estudantes consideraram as aulas dos professores como boa ou ótima. Esse alinhamento era uma condição esperada, visto que os estudantes tendem a condicionar o seu bom rendimento nas aulas com a qualidade das mesmas.

Quanto às avaliações negativas, a taxa de reprovação foi relativamente baixa comparada com a taxa que se esperava obter, isto porque observando os comentários dos estudantes, nota-se que a maior parte deles são negativos com relação ao Ensino de Física. Chama a atenção o índice de reprovação do IFMT Campus Confresa, visto que, mesmo não tendo as condições ideais sugeridas para boas aulas, ainda é a escola mais estruturada do município, e a única que oferece laboratório para a prática de aulas de Física e biblioteca.

Discutir estes dados implica entrar em pontos mais profundos, como a formação dos professores, condições de trabalho dos mesmos, questões que, como se sabe, são fundamentais para a prática de boas aulas, e, das três escolas pesquisadas, até o período de coleta de dados, apenas o IFMT possui professores formados em Física, e as demais escolas ainda não possui a estrutura básica presente no IFMT.

Além destes pontos, a forma de trabalho da escola também é um fator que tem forte influência nesta avaliação das aulas, das 3 escolas, a Tiradentes mantém uma disciplina mais rígida, tanto em relação ao comportamento dos estudantes, quanto metodologias de trabalho dos professores, e a escola 29 de Julho os professores têm maior autonomia para planejamento de suas aulas.

E neste ponto IFMT é quem mais se aproxima dos modelos educacionais indicados por educadores, pois durante o diálogo com os estudantes verificou-se que há uma abertura para que os mesmos possam construir o próprio conhecimento, sem necessariamente ter que absorver apenas o que o professor ensina.

A Questão 3 foi uma questão aberta e os estudantes poderiam responder livremente, "Cite 3 motivos que você acredita que atrapalham o seu rendimento nas aulas de física?” As respostas chamaram a atenção por não terem uma grande 
variação. Identificou-se que, apesar das diferentes maneiras de expressão, as respostas se encaixam em blocos bem definidos de motivos, dos quais se destacam, conversas paralelas, distrações (smartphone, músicas, brincadeiras, perguntas aleatórias fugindo do tema), falta de interatividade das aulas, más condições físicas das salas, dificuldade do professor em explanar as aulas, entre outras. Os dois fatores que mais se repetiram foram: conversas paralelas e distrações em geral.

Com isso foi analisado que primeiro, os estudantes tiveram certa sinceridade ao responder o questionário, segundo nos mostrou que eles admitem que o principal problema nas salas de aulas que contribui para o insucesso do processo de ensino-aprendizagem, é a conversa paralela entre eles. As Figuras 1, 2 e 3, são respostas de estudantes das três instituições.

Figura 1 - Resposta Estudante T15.

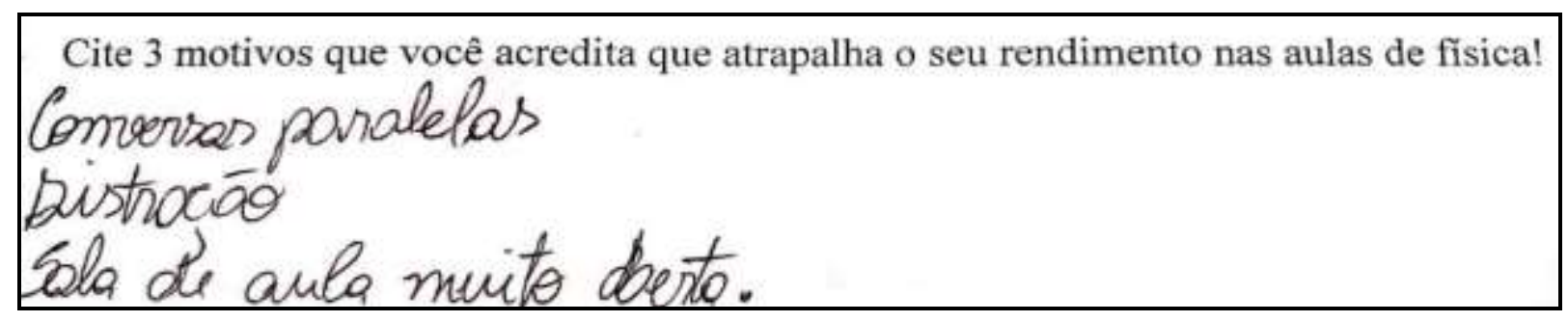

Fonte: Dados da pesquisa (2020).

Figura 2 - Resposta Estudante I12.

\section{Cite 3 motivos que você acredita que atrapalha o seu rendimento nas aulas de fisica! Conversa, acsenteresse, os valunos...}

Fonte: Dados da pesquisa (2020).

Figura 3 - Resposta Estudante J31.

\section{Cite 3 motivos que você acredita que atrapalha o seu rendimento nas aulas de física!

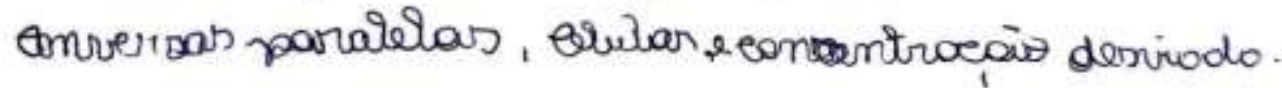

Fonte: Dados da pesquisa (2020).

Deve-se evidenciar ainda os principais motivos do baixo rendimento em Física: falta de interesse pessoal do estudante, falta de interatividade nas aulas, dificuldade em compreender a explicação do professor, falta de laboratório de Física, más condições físicas das salas, dificuldade com cálculo básico e poucas aulas da disciplina. Os dados obtidos se assemelham às observações de Costa \& Barros (2015) e Moreira (2018), quando apontam os principais obstáculos enfrentados no Ensino de Física.

Motivos estes que nos trazem a percepção de que os estudantes têm plena consciência das condições escolares em que estão inseridos e conseguem identificar com certa facilidade em apontar as falhas e os problemas do processo de ensinoaprendizagem, o que é um ponto muito positivo, pois esta visão crítica deve ser estimulada a todo momento para a construção do cidadão crítico e reflexivo.

Para analisar os dados obtidos da questão 4: "De uma forma geral você considera as aulas satisfatórias para a completa aprendizagem do conteúdo? Justifique. É preciso ponderar que, sabemos que no modelo de ensino que utilizamos é 
impossível obter uma aprendizagem completa de qualquer conteúdo, e talvez nenhum sistema de ensino no mundo tenha esta capacidade, devido a imensa diversidade de personalidades concentradas em um mesmo ambiente. Entretanto esta pergunta foi formulada com a intenção de levar o estudante a refletir não somente sobre a aprendizagem própria, mas sobre a aprendizagem de um modo geral da turma.

Mais uma vez, como nas perguntas anteriores, é possível notar um padrão de respostas entre os estudantes mesmo se tratando de escolas distintas. Os estudantes da Escola Tiradentes foram os que pior avaliaram suas aulas, 65,11\% deles não consideram as aulas satisfatórias, e apresentaram como principal justificativa a falta de aulas práticas e experimentos, seguida de má explanação do conteúdo pelo professor e pouco tempo de aula por semana. Os outros 31,39\% avaliaram como satisfatórias, porém utilizando como justificativa o esforço do professor para ministrar a aula e o esforço próprio para compreender o conteúdo.

Os estudantes da Escola 29 de julho por sua vez também em sua maioria dos que responderam à questão classificaram as aulas como insatisfatórias, justificando como motivos a falta de convicção dos professores ao ministrarem as aulas e a dificuldade pessoal em compreender o conteúdo, citaram ainda como justificativa, falta de um laboratório da disciplina, pouco tempo de aula e falta de diálogo com os professores para esclarecimento de dúvidas.

Deve-se destacar que as Escolas Tiradentes e 29 de Julho não possuem professores licenciados em Física, a falta de profissionais da área é outro obstáculo para o um ensino de qualidade (Costa \& Barros, 2015).

Os que avaliaram positivamente as aulas e as consideram satisfatórias para o aprendizado do conteúdo, justificaram que estão conseguindo aprimorar seus conhecimentos e que os professores conseguem passar o conteúdo com lucidez. Contudo, temos um total de $22,64 \%$ que não responderam essa questão.

O maior percentual de satisfação entre as escolas foi dos estudantes do IFMT (47,14\%), entretanto, nem todos justificaram suas respostas, e aqueles que justificaram, citaram como motivo a boa explicação do professor, facilidade em aprender o conteúdo e o fato de ter aulas interativas e experimentais. Reis \& Macêdo (2015), fazem menção da importância das aulas práticas, pois existe uma tendência de maior participação e interesse dos estudantes em aulas mais dinâmicas e interativas, além da experimentação o IFMT é a instituição com mais recursos didáticos e professores mais qualificados

Nem todos que avaliaram negativamente justificaram também, mas, alguns apontaram como contrapontos a falta de domínio do conteúdo por parte do professor, pouco tempo de aulas práticas e dificuldade em compreender o conteúdo de maneira geral.

A questão 5: Indique os principais pontos que de acordo com sua visão ajudaria a melhorar o processo de ensinoaprendizagem do conteúdo de Física, talvez seja a pergunta mais importante, e que pode interessar futuros estudos. Ao terem oportunidade de elencar os possíveis pontos que podem melhorar o processo de ensino-aprendizagem em Física, pode ser feito uma análise e propor possíveis mudanças para que haja progresso no processo no Ensino de Física, esta importância está no fato de que o estudante é a parte principal do sistema educacional.

Os resultados obtidos, como já era esperado, foram os mais variados possíveis. Esta variação está intrinsecamente ligada com a imensa diversidade de formas de pensar e enxergar o meio ao qual está inserido cada estudante, entretanto apesar destas diferenças, foi possível notar um padrão nas respostas, embora as respostas estivessem apenas escritas de forma diferente, mas abordavam o mesmo tema. Para facilitar a compreensão e a fluidez da leitura, os resultados obtidos foram analisados e triados para os tópicos aos quais se referiam, assim foi possível organizar as diversas respostas e apresentá-las no Quadro 3. 
Quadro 3 - Tópicos a serem ajustados de acordo com a percepção dos estudantes.

\begin{tabular}{|c|c|c|c|c|c|c|}
\hline \multirow[t]{3}{*}{ Tópicos } & \multicolumn{6}{|c|}{ Porcentagem de citações por escola } \\
\hline & \multicolumn{2}{|l|}{29 de julho } & \multicolumn{2}{|l|}{ Tiradentes } & \multicolumn{2}{|c|}{$\begin{array}{ll}\text { IFMT } & \text { Campus } \\
\text { Confresa } & \end{array}$} \\
\hline & Porcentagem & $\begin{array}{l}\mathrm{N}^{\mathrm{o}} \mathrm{de} \\
\text { estudantes }\end{array}$ & Porcentagem & $\begin{array}{l}\mathrm{N}^{\mathrm{o}} \mathrm{de} \\
\text { estudantes }\end{array}$ & Porcentagem & $\begin{array}{l}\mathrm{N}^{\mathrm{o}} \mathrm{de} \\
\text { estudantes }\end{array}$ \\
\hline $\begin{array}{l}\text { Melhorar a explicação } \\
\text { dos conteúdos em sala }\end{array}$ & $21,49 \%$ & 23 & $12,79 \%$ & 11 & $18,57 \%$ & 13 \\
\hline $\begin{array}{l}\text { Mais aulas interativas e } \\
\text { práticas }\end{array}$ & $45,79 \%$ & 49 & $46,71 \%$ & 40 & $17,14 \%$ & 12 \\
\hline $\begin{array}{l}\text { Relacionamento mais } \\
\text { próximo entre } \\
\text { professor/estudante }\end{array}$ & $13,08 \%$ & 14 & $9,30 \%$ & 8 & $5,71 \%$ & 4 \\
\hline $\begin{array}{l}\text { Aumento do tempo de } \\
\text { aula da disciplina }\end{array}$ & $19,62 \%$ & 21 & $10,46 \%$ & 9 & $1,42 \%$ & 1 \\
\hline $\begin{array}{l}\text { Melhorar a estrutura } \\
\text { física da escola }\end{array}$ & $12,14 \%$ & 13 & $13,95 \%$ & 12 & Não citado & 0 \\
\hline $\begin{array}{l}\text { Aumentar o interesse } \\
\text { próprio para a } \\
\text { disciplina }\end{array}$ & $9,34 \%$ & 10 & Não citado & 0 & $5,71 \%$ & 4 \\
\hline $\begin{array}{l}\text { Professor formado na } \\
\text { disciplina }\end{array}$ & Não citado & 0 & $23,25 \%$ & 20 & Não citado & 0 \\
\hline $\begin{array}{l}\text { Mais livros e materiais } \\
\text { de estudo }\end{array}$ & Não citado & 0 & $8,13 \%$ & 7 & Não citado & 0 \\
\hline Não responderam & $28,03 \%$ & 30 & $3,48 \%$ & 3 & $51,42 \%$ & 36 \\
\hline
\end{tabular}

* A soma dos percentuais resultará em números maiores que $100 \%$ devido ao fato de que, os estudantes que responderam a esta questão citaram mais de um motivo por resposta. Fonte: Dados da pesquisa (2020).

A partir da análise dos dados foi possível verificar que os pontos abordados pelos estudantes condizem com aqueles que são frequentemente abordados em debates, congressos e comissões responsáveis por pensar a educação no Brasil. Trechos citados no decorrer deste trabalho fornecem exemplos destas abordagens.

Primeiro tópico que merece o destaque na nossa discussão, foi o tópico citado pela maioria absoluta dos estudantes que responderam a esta questão, a necessidade que se mude a metodologia das aulas de Física de uma vez por todas, adotando aulas mais interativas e práticas, Moreira (2018) reforça essa ideia ao mencionar que metodologias tradicionais não facilitam o processo de ensino-aprendizagem e ainda atuam como uma agravante.

A discussão acerca da utilização de experimentos em sala de aulas já é antiga, e apesar de parecer meio óbvio que seja necessário a experimentação em sala como complemento das aulas, ainda não existe consenso entre os educadores, aqueles que defendem a ideia, citam a importância da prática experimental como fator motivador e estimulante do estudante para a aprendizagem, entretanto aqueles que não concordam com esta experimentação em sala, defendem que o uso de experimentos como complemento é perca de tempo e serve apenas para comprovação de teorias já explanadas (Reis \& Macêdo, 2019). Borges (2002) ainda lembra da importância não apenas manipular objetos em laboratórios mas, aproximar as aulas práticas do fazer ciências.

Outro tópico que se destaca, principalmente nas escolas do Estado de Mato Grosso, é a quantidade de aulas na disciplina de Física, que é de apenas uma aula por semana, algo totalmente impensável para uma disciplina de tamanha importância e complexidade. 
Foi citado ainda que deve haver um relacionamento mais próximo entre professor e estudante, este inclusive, foi o tema principal nos diálogos antes da aplicação do questionário, e, este é um ponto que chama a atenção pois, se pensarmos em um ensino mais humanizador, essa aproximação deixa de ser uma queixa tão significativa, constatada nas respostas dos estudantes. Cabe destacar que Morais (2009) enfatiza a importância de ouvir os anseios dos estudantes para melhorar o processo de ensino-aprendizagem e tornar as aulas mais interessantes e atrativas.

Explicações mais claras e coesas por parte do professor durante as aulas também foi um tópico de destaque nas respostas, um problema que pode ser justificado pela não formação acadêmica em Física dos professores que ministram a disciplina, o que é algo significativo, pois o professor não tem as bases suficientes para dominar os conteúdos de forma que ele consiga simplificar explicações para o estudante.

E um último destaque que chamou a atenção é que 32\% não responderam a esta questão, e não citaram nenhum ponto que poderia ser melhorado. O número chama mais a atenção quando observamos as escolas de forma individual, e dos estudantes pesquisados no IFMT Campus Confresa 51,42\% não responderam.

O que pode ter ocorrido foi a falta de senso crítico desses estudantes para analisar o meio ao qual estão inseridos e identificar os problemas que os afetam para assim pensar possíveis soluções para estes problemas, e esta ótica nos revela uma falha profunda no sistema educacional, pois além de serem parte fundamental do processo de ensino-aprendizagem.

A Questão 6 trouxe uma problemática que está em constante debate nas discussões educacionais dos dias atuais, e questionou os estudantes o número de aulas que eles tinham e se eles consideram este número suficiente para sua aprendizagem dos conteúdos, "Quantas aulas por semana você tem da disciplina de física? Você considera a quantidade de aulas semanais suficiente para a sua aprendizagem?" Os resultados obtidos seguem expressos no Quadro 4 a seguir quantificados de acordo com o número de estudantes que responderam:

Quadro 4 - suficiência das aulas de física na percepção dos estudantes.

\begin{tabular}{|c|c|c|c|c|c|c|}
\hline Suficiência das aulas & \multicolumn{2}{|c|}{29 de julho } & \multicolumn{2}{c|}{ Tiradentes } & \multicolumn{2}{c|}{ CFMT Campus } \\
& & & & \\
& 1 aula & 2 aulas & 1 aula & 2 aulas & 1 aula & 2 aulas \\
\hline Suficiente & 6 & 31 & & 27 & & 30 \\
\hline Insuficiente & 20 & 35 & & 51 & & 36 \\
\hline Não responderam & \multicolumn{2}{|c|}{15} & 8 & & 4 \\
\hline
\end{tabular}

Fonte: Dados da pesquisa (2020).

Primeiro ponto que se pode destacar é o fato de que apenas o modelo estadual básico ainda dispõe de uma matriz curricular com apenas uma aula semanal, as outras escolas todas dispõem de matrizes curriculares com duas aulas semanais da disciplina, ou seja, o dobro da carga horária. O que se percebe na visão dos estudantes é que em todos os casos independentemente do número de aulas, a maioria dos que responderam à questão, consideram o número de aulas insuficiente para a aprendizagem do conteúdo, isto nos revela o quanto este problema é relevante para o processo de ensinoaprendizagem, problemática apontada por Costa \& Barros (2015).

O aumento do número de aulas da disciplina de Física é um tema que envolve uma discussão mais profunda, pois passa necessariamente por dois processos delicados e complicados de serem aplicados, o primeiro deles seria a redução do número de aulas de outras disciplinas, o que é algo inconcebível, dadas as condições que se encontram as matrizes escolares 
de escolas que funcionam em meio período, não seria possível remover aulas de outras disciplinas que também já funcionam com cargas horárias mínimas para um ensino em tempo parcial.

Assim a solução deste problema passaria pelo aumento da carga horária dos cursos do Ensino Médio de Tempo Parcial, e aqui entra a discussão, pois aumentar essa carga horária implicaria em uma mudança para o ensino de Tempo Integral. Para tanto, seria necessário aumentar o investimento, e ao observar o ínfimo orçamento que muitas escolas dispõem no momento, duplicar os gastos não parece concebível neste momento, portanto, a discussão para este tema deve se basear em cima do aumento do orçamento para as escolas.

\section{Considerações Finais}

O presente estudo teve como objetivo avaliar a percepção dos estudantes sobre a relação ensino-aprendizagem na disciplina de Física e identificar os problemas citados por eles que dificultam de alguma forma esta relação. Um dos principais resultados obtidos é que 58,17\% dos estudantes avaliam o Ensino de Física como ótimo ou bom e as problemáticas apontadas pelos estudantes são: dificuldade de explicação dos professores, distrações, falta de interesse, mau comportamento em sala de aula, as más condições físicas das escolas e falta de laboratórios de Física.

Ficou evidente que existe um quantitativo significativo de estudantes insatisfeitos com o Ensino de Física. A insatisfação desses estudantes está diretamente relacionada aos métodos de ensino utilizados pelos professores, que em maioria são aulas engessadas, sem novidades, atrativos, que visem motivar os estudantes e a falta de aulas experimentais. Esses são problemas crônicos do Brasil, como a falta de professores graduados em Física e que tenham acesso a formação adequada.

Vários pontos apontados pelos estudantes já são alvo de discussões a muito tempo, porém seguem sem soluções práticas até o presente momento. Contudo, algumas soluções já são conhecidas, apenas não foram colocadas em prática ainda, como por exemplo maior investimento em educação.

Os resultados obtidos superaram as expectativas iniciais, ao mostrar que a maior parte dos estudantes pesquisados conseguiu refletir de forma crítica sobre seu processo de aprendizagem. Estes resultados podem embasar futuras discussões sobre o Ensino de Física, mas essa discussão precisa envolver toda a comunidade escolar, para que as mudanças implementadas atendam as reais problemáticas enfrentadas pelos estudantes. E foi com esse intuito que se desenvolveu essa pesquisa, para ouvir os anseios e dificuldades dos estudantes.

Essa pesquisa pode interessar pesquisadores e professores, sejam em formação inicial ou contínua, que atuam com o Ensino de Física. Pode auxiliar ainda as diversas esferas da comunidade escolar a mudar procedimentos em busca de melhorias para o processo de ensino como um todo, e dessa forma desenvolver e melhorar suas metodologias de aulas.

\section{Referências}

Almeida Júnior, J. B. (1980). A evolução do ensino de Física no Brasil (2ª parte). Revista Brasileira de Ensino de Física, São Paulo. 2 (1), 55-73. http://www.sbfisica.org.br/rbef/pdf/vol02a06.pdf.

Barros, M. \& Martins, S. (2020). Artefatos digitais para o Museu DICA: contribuições para a formação de professores de Física. Caderno Brasileiro de Ensino de Física. 37(1), 283-314. https://periodicos.ufsc.br/index.php/fisica/article/view/2175-7941.2020v37n1p283/42904.

Borges, A. T (2002). Novos rumos para o laboratório escolar de ciências. Caderno Brasileiro de Ensino de Física. 19(3), 291-313. https://periodicos.ufsc.br/index.php/fisica/article/view/6607.

Cardoso. D. (2020). Mídia, Ciência e Ensino> Análise de materiais desenvolvidos por licenciandos em Física. Caderno Brasileiro de Ensino de Física. 37(3), 1628-1658. https://periodicos.ufsc.br/index.php/fisica/article/view/75000/44959.

Coelho, A. L. M. de B. (2021). Aspectos sobre a visão humana em uma abordagem interdisciplinar no ensino médio. Caderno Brasileiro de Ensino de Física. 38,(2), 1096-1112. https://periodicos.ufsc.br/index.php/fisica/article/view/76672/47325. 
Costa, L. G. \& Barros, M. A. (2015). O ensino da física no brasil: problemas e desafios. EDUCERE, 2015. https://educere.bruc.com.br/arquivo/pdf2015/21042_8347.pdf.

Creswell, J. W. (2007). Projeto de pesquisa: métodos qualitativo, quantitativo e misto; tradução Luciana de Oliveira da Rocha - 2. Ed. - Porto Alegre, Artmed, 2007.

Durkheim, É. (2011). Educação e sociologia. Tradução. Stephania Matousek. Petrópolis: Vozes, 2011 - (Coleção textos fundantes de Educação). Evolução histórica do processo ensino-aprendizagem. https://pedropeixotoferreira.files.wordpress.com/2015/02/durkheim_2011_educacao-e-sociologia_book.pdf.

Fernandes, J., Guimarães, M. H. U., Robert, A. e Passos, M. M. (2020). Estudo da evasão dos estudantes de Licenciatura e Bacharelado em Física: uma análise à luz da Teoria do Sistema de Ensino de Bourdieu. Caderno Brasileiro de Ensino de Física. 37(1), 105-126. https://periodicos.ufsc.br/index.php/fisica/article/view/2175-7941.2020v37n1p105/42895.

Ferreira, G. K. e Custódio, J. F. (2021). Cenários do debate sobre a natureza da ciência nos cursos de Licenciatura em Física no Brasil. Caderno Brasileiro de Ensino de Física. 38(2), 1022-1066. https://periodicos.ufsc.br/index.php/fisica/article/view/74094/47132.

Haidar, M. L. M.(1972). O ensino secundário no império brasileiro. São Paulo: Gribaldo, USP.

Martins, J. T. \& Oliveira, E. A. G. (2020). Atividades experimentais de Física da revista Ciência Hoje e das Crianças. Caderno Brasileiro de Ensino de Física. 37(2), 455-478, ago. 2020. https://periodicos.ufsc.br/index.php/fisica/article/view/2175-7941.2020v37n2p455/43902.

Moreira, M. A. (2018). Uma análise crítica do ensino de Física. Estudos Avançados. 92(34). https://www.scielo.br/scielo.php?script=sci_arttext\&pid=S0103-40142018000300073.

Pereira, M. M. (2020). Sentidos do (e no) Ensino de Física no Ensino Médio: articulações com a teoria histórico-cultural. Caderno Brasileiro de Ensino de Física. 37(1), 1-5. https://periodicos.ufsc.br/index.php/fisica/article/view/2175-7941.2020v37n1p1/42907.

Pszybylski, R. F.; Motta, M. S. \& Kalinke, M. A. (2020). Uma revisão sistemática sobre as pesquisas realizadas em programas de mestrado profissional que versam sobre a utilização de smartphones no Ensino de Física. Caderno Brasileiro de Ensino de Física. 37(2), 406-427. https://periodicos.ufsc.br/index.php/fisica/article/view/2175-7941.2020v37n2p406/43900.

Reis, W. F. \& Macêdo, J. A. (2015). Um estudo sobre a importância das atividades experimentais dos livros didáticos para o ensino de física. Revista Científica Semana Acadêmica. 75(1). https://semanaacademica.org.br/system/files/artigos/artigo_-_wendel_e_josue_1.pdf.

Ricardo, E. C. \& Freire, J. C. A. (2007). A concepção dos alunos sobre a física do ensino médio: um estudo exploratório. Revista Brasileira de Ensino de Física. 29(2), 251-266. https://www.scielo.br/scielo.php?script=sci_arttext\&pid=S1806-11172007000200010\&lng=pt\&tlng=pt.

Sampaio, G. M. D. (2004). A História do Ensino de Física no Colégio Pedro II de 1838 até 1925. Dissertação (Mestrado). Universidade Federal do Rio de Janeiro, Rio de Janeiro. http://146.164.248.81/hcte/docs/dissertacoes/2004/glads_maria_delia_sampaio.pdf.

Sestari, F. B.; Garcia, I. K. \& Santarosa, M. C. P. (2021). Ações interdisciplinares no ensino de Física: Pressupostos teóricos e revisão da literatura. Caderno Brasileiro de Ensino de Física. 38(2), 883-913. https://periodicos.ufsc.br/index.php/fisica/article/view/67750/47045.

Silva, J. P.; Toledo, T. A. \& Carbo, L. Estado da arte: utilização do método investigativo na disciplina de Física no período de 2013-2018. Revista Prática Docente. 5(1), 344-359, jan/abr 2020. http://periodicos.cfs.ifmt.edu.br/periodicos/index.php/rpd/article/view/622/274. 